\title{
EL LÉXICO DE LOS EJEMPLOS DE LAS GRAMÁTICAS DE ESPAÑOL COMO LENGUA EXTRANJERA
}

\author{
Diana Esteba Ramos \\ Universidad de Málaga \\ desteba@uma.es
}

\begin{abstract}
Resumen
Un corpus de ocho gramáticas de español como lengua extranjera es analizado en este artículo desde la consideración del caudal léxico que incluyen como ejemplos en los apartados nominales. Estas voces se estudian teniendo en cuenta cuestiones como la rentabilidad o frecuencia léxica, todo ello con el fin de mostrar una reflexión sobre la utilidad de la selección de estos elementos para el proceso de enseñanzaaprendizaje de una lengua.
\end{abstract}

PALABRAS CLAVE: Español como lengua extranjera, Gramática, Análisis de materiales, ejemplos

\begin{abstract}
A group of eight grammars of Spanish as a Foreign Language is analyzed in this article from the point of view of the lexical items that are included as examples in the nominal sections. These voices are studied taking into account questions like effectiveness or lexicon frequency, all of this with the purpose of sharing insight into the use of these elements in the teaching and learning process of a language.
\end{abstract}

KEY WORDS: Spanish as a foreign language, Grammar, Materials Analysis, Exemples

\section{Introducción}

Los estudios en torno a la lingüística aplicada son muy abundantes y abarcan diversos ámbitos de investigación. Dentro de estos, el análisis de materiales de español como lengua extranjera se ha inclinado preferentemente por los manuales de clase ${ }^{1}$, dejando en un segundo plano las gramáticas, cuyo estudio se ha acometido solo de manera parcial. En efecto, más que el análisis de las gramáticas publicadas, se ha realizado una profundización en cuestiones gramaticales de dificultad, ofreciendo propuestas de codificación adaptadas a los alumnos y a sus necesidades.

Ello nos ha llevado a emprender un estudio de un corpus de gramáticas actuales del español como lengua extranjera desde un ámbito que ha sido escasamente explotado hasta el momento ${ }^{2}$ : el de los ejemplos. Más concretamente, analizaremos los ítems léxicos que se utilizan en los textos para ejemplificar la doctrina relacionada con el artículo y el nombre.

1 Malinowski (2000), por ejemplo, analiza los defectos de los materiales polacos, mientras que Lenoir (2000) hace un repaso de las características de los manuales franceses publicados entre 1988 y 1997, atendiendo especialmente a la tipología de actividades y ejercicios.

2 Tenemos constancia de análisis en profundidad del léxico de manuales de español, como es el caso de Maciel (1994) o Izquierdo Gil (2004). Asimismo, Benítez y Zebrowski analizaron en un artículo los manuales polacos 
Con esta aproximación pretendemos contribuir a la necesaria interrelación entre las investigaciones en E.LE y la práctica real que se lleva al aula a través de los textos seleccionados para tal fin ${ }^{3}$. Sin duda, una óptima selección de ejemplos en las gramáticas redundaría en una mejora en el aprendizaje del alumno: no creemos que la aparición de nuevas voces en estos textos constituya por sí misma un incremento del caudal léxico de los estudiantes ${ }^{4}$, pero sí estamos convencidos de que un control consciente sobre este va a facilitar la tarea del aprendiente. Si la planificación del léxico que aprenden los estudiantes debe ser importante en nuestras clases, podríamos contribuir a su refuerzo teniendo en cuenta factores como este $^{5}$. Por ello queremos partir del análisis de los materiales gramaticales para observar qué palabras utilizan para la ejemplificación y proponer, si fuera necesario, una implementación de los ejemplos atendiendo a razones de frecuencia y disponibilidad léxica.

\subsection{Presentación del corpus}

Hemos conformado un corpus que incluye gramáticas muy diversas aparecidas en España entre 1980 y 2005 . Hemos seleccionado los textos que acompañan a los manuales Español 2000 y Español en directo, muestras más significativas del método situacional en manuales de español aparecidos en nuestro país, además de gramáticas de corte eminentemente comunicativo ${ }^{6}$. Por ello, estamos trabajando con materiales pertenecientes a diferentes corrientes pero homogeneizados de alguna manera por el hecho de haber sido publicados aproximadamente en el último cuarto de siglo en España ${ }^{7}$.

Se trata de textos que están en algunos casos ideados para la consulta de los profesores y otros que se dirigen preferentemente a los alumnos; dentro de estos, también hemos contado con algunos que restringen el nivel de competencia gramatical del estudiante al que se dirigen y otros en los que no se hace alusión a los conocimientos en lengua española de los

(1993) y aquel presentó un estudio sobre el léxico real e irreal en los materiales de E.LE (1994). No obstante, no conocemos estudios parecidos al que proponemos.

3 Si bien los enfoques estructuralistas trajeron consigo las investigaciones científicas en torno a la lengua para ponerlas a disposición del profesor en el aula, los métodos comunicativos abandonan parcialmente estos avances. En lo que a nuestro trabajo respecta, la cuidada selección léxica del estructuralismo a través de listados de frecuencia da paso a la apuesta por los métodos de aprendizaje de vocabulario implícitos en textos reales en los que no se controla todo el caudal transmitido (Puren: 1998). Creemos que entre ambas posturas entendidas en sus más rígidos extremos existe una posibilidad de síntesis de argumentos necesaria para la evolución de la didáctica.

4 Dentro de las dos formas en las que se puede trabajar el léxico, explícita e implícita, el recurso al vocabulario en los ejemplos de las gramáticas contribuiría al trabajo implícito de estas unidades. Es evidente, en cualquier caso, que es necesario seguir un proceso largo y gradual para aprender una unidad léxica y que con estas apariciones en las gramáticas simplemente se cubriría una parte de dicho proceso.

Para algunos autores, este tipo de aprendizaje implícito sería más conveniente en los niveles más altos de la enseñanza de una lengua (Gómez Molina, 2001). En cualquier caso, también se ha defendido el que las palabras frecuentes deban ser objeto tanto de aprendizaje explícito como implícito (Nation, 2001: 16).

5 Hay estudios como el de De Miguel (2005: 15) que señalan que «solo un tercio del profesorado de ELE afronta el reto de la didáctica del léxico de una manera planificada y responsable». Querríamos, siguiendo a Gómez Molina (2004), hacer hincapié en la necesidad de una programación de estos elementos.

6 Cfr. A. Sánchez (1992: 393-396).

7 No es este el lugar de hacer un recorrido a través de la metodología de las lenguas extranjeras; véase para ello, entre otros, Richards y Rodgers ([1998] 2003) y Puren (1998) en lo que respecta a la enseñanza de lenguas en general, y Sánchez Pérez (1992) en lo que se refiere a la historia de la enseñanza del español como lengua extranjera. 
alumnos que van a hacer uso de la gramática. En principio, visto su lugar de publicación y considerado el hecho de que no se dirigen a hablantes de una lengua extranjera determinada, se trataría de textos no creados ad hoc para un medio exolingüe, aunque en ellos no se indica nada al respecto ${ }^{8}$.

En suma, perseguimos trabajar con un corpus heterogéneo que nos permita presentar un primer acercamiento al tema a través de una visión de conjunto del campo de las últimas gramáticas de español como lengua extranjera publicadas en España.

Tabla 1

\begin{tabular}{|c|c|}
\hline \multicolumn{2}{|l|}{ Texto 1: Alo } \\
\hline $\begin{array}{l}\text { Descripción } \\
\text { bibliográfica }\end{array}$ & $\begin{array}{l}\text { AlONSO RAYA, RosARIO et alii (2005): Gramática básica del es- } \\
\text { tudiante de español. Barcelona, Difusión. }\end{array}$ \\
\hline $\begin{array}{l}\text { Determinación de } \\
\text { público meta }\end{array}$ & $\begin{array}{l}\text { - Alumnos de A1, A2 y B1. } \\
\text { - Se señala asimismo que pueden utilizarla los alumnos de } \\
\text { competencia superior que quieran encontrar nuevas explicacio- } \\
\text { nes a problemas clásicos relacionados con el español. } \\
\text { - Para su elaboración los autores aseguran haber tenido en } \\
\text { cuenta el nivel de lengua del destinatario en las muestras de } \\
\text { lengua utilizadas. }\end{array}$ \\
\hline $\begin{array}{l}\text { Descripción de otros } \\
\text { aspectos significativos }\end{array}$ & $\begin{array}{l}\text { - Clave al final del volumen, junto con un elenco de verbos } \\
\text { conjugados: puede utilizarse tanto para el aprendizaje autóno- } \\
\text { mo como para el aula de español. } \\
\text { - Los ejemplos aparecen destacados en letra cursiva. Junto a } \\
\text { ellos, entre corchetes grises, en ocasiones se encuentran ciertas } \\
\text { explicaciones. }\end{array}$ \\
\hline
\end{tabular}

8 En el medio endolingüe la lengua extranjera se encuentra en el entorno del estudiante como vehículo de socialización; sin embargo, en el exolingüe el estudiante se encuentra en su país de origen o en otro cuya lengua materna no es la que está aprendiendo en el aula. Cfr. García Santa Cecilia (2000: 80). En el medio exolingüe el alumno deberá ser expuesto en el aula más veces a unidades léxicas y las pretensiones de los profesores en cuanto al número de unidades que enseñar deberán ser más modestas; en el medio endolingüe, por el contrario, el alumno tiene acceso a un input incontrolable por parte del profesor. Cfr. Izquierdo Gil (2004: 26).

Es sabido que las lenguas románicas comparten el origen de unas unidades léxicas básicas que hacen comprensible un número importante de voces que se relacionan con aspectos fundamentales de la vida del hombre, sus necesidades materiales y afectivas así como su entorno doméstico (Reinheimer y Tasmowski, 1997: 59-60). No obstante, dado que no tenemos constancia de la lengua materna del público receptor, no sabemos si esta puede ser una facilidad añadida para la comprensión de muchos ejemplos o no. 
Tabla 2

\begin{tabular}{|l|l|}
\hline \multicolumn{2}{|l|}{ Texto 2: Lop } \\
\hline Descripción bibliográfica & $\begin{array}{l}\text { LóPEz GARCíA, ÁNGEL (2005): Gramática cognitiva para } \\
\text { profesores de español L2. Madrid, Arco/Libros. }\end{array}$ \\
\hline $\begin{array}{l}\text { Determinación } \\
\text { de público meta }\end{array}$ & $\begin{array}{l}\text { Gramática cognitiva destinada en exclusividad a los profe- } \\
\text { sores de español como lengua segunda. }\end{array}$ \\
\hline $\begin{array}{l}\text { Descripción de otros } \\
\text { aspectos significativos }\end{array}$ & $\begin{array}{l}\text { Los ejemplos del texto no aparecen diferenciados en párra- } \\
\text { fos independientes de la explicación gramatical. }\end{array}$ \\
\hline
\end{tabular}

Tabla 3

\begin{tabular}{|l|l|}
\hline \multicolumn{2}{|l|}{ Texto 3: Gut } \\
\hline Descripción bibliográfica & $\begin{array}{l}\text { GutiérREz ArAus, MARía Luz (2004): Problemas fundamen- } \\
\text { tales de la gramática del español como 2/L. Madrid, Arco/ } \\
\text { Libros. }\end{array}$ \\
\hline $\begin{array}{l}\text { Determinación } \\
\text { de público meta }\end{array}$ & $\begin{array}{l}\text { Su objetivo fundamental es la reflexión sobre el sistema gra- } \\
\text { matical de la lengua española para poder instruir a aprendices } \\
\text { y preparar materiales para la clase }\end{array}$ \\
\hline $\begin{array}{l}\text { Descripción de otros } \\
\text { aspectos significativos }\end{array}$ & $\begin{array}{l}\text { Los ejemplos aparecen separados de las explicaciones gra- } \\
\text { maticales, aunque no se utiliza ningún procedimiento para } \\
\text { destacarlos. }\end{array}$ \\
\hline
\end{tabular}

Tabla 4

\begin{tabular}{|l|l|}
\hline \multicolumn{2}{|l|}{ Texto 4*: Cas } \\
\hline Descripción bibliográfica & $\begin{array}{l}\text { CASTRO VIUDEZ, FRANCISCA (2004): Aprende gramática y vo- } \\
\text { cabulario 1. Madrid, Sociedad General Española de Librería. }\end{array}$ \\
\hline $\begin{array}{l}\text { Determinación } \\
\text { de público meta }\end{array}$ & Estudiantes del A1. \\
\hline $\begin{array}{l}\text { Descripción de otros } \\
\text { aspectos significativos }\end{array}$ & $\begin{array}{l}\text { - En el libro se encuentran 30 temas de gramática y 14 de } \\
\text { zocabulario con solucionario, lo que implica que puede utili- } \\
\text { - Los temas se estructuran en torno a una situación inicial, } \\
\text { a la que le siguen una conceptualización y los ejercicios } \\
\text { correspondientes. }\end{array}$ \\
\hline
\end{tabular}

\footnotetext{
* Está dentro del corpus utilizado por Varela (2006): puede verse allí la descripción en lo que respecta al vocabulario de este texto (2006: 44-46).
} 
Tabla 5

\begin{tabular}{|c|c|}
\hline \multicolumn{2}{|l|}{ Texto 5: Lob } \\
\hline Descripción bibliográfica & $\begin{array}{l}\text { SÁNCHEZ Lobato, Jesús y Nieves GarCía Fernández (1999 } \\
\text { [1996]): Español 2000. Gramática. Madrid. Sociedad Gene- } \\
\text { ral Española de Librería. }\end{array}$ \\
\hline $\begin{array}{l}\text { Determinación } \\
\text { de público meta }\end{array}$ & $\begin{array}{l}\text { - Texto dirigido a los estudiantes como apoyo a Español } 2000 . \\
\text { - Concebido para que cualquier alumno de español pueda uti- } \\
\text { lizarlo desde cualquier posición didáctica. } \\
\text { - Se indica también que puede ser de utilidad para el hablante } \\
\text { nativo porque se estudia la norma culta. }\end{array}$ \\
\hline $\begin{array}{l}\text { Descripción de otros } \\
\text { aspectos significativos }\end{array}$ & $\begin{array}{l}\text { - Los ejemplos aparecen en cursiva y diferenciados de las } \\
\text { indicaciones gramaticales. } \\
\text { - En algunos casos incluso los ítems aparecen ordenados } \\
\text { alfabéticamente. }\end{array}$ \\
\hline
\end{tabular}

Tabla 6

\begin{tabular}{|c|c|}
\hline \multicolumn{2}{|l|}{ Texto 6: Gon } \\
\hline Descripción bibliográfica & $\begin{array}{l}\text { GonzÁlez Hermoso, A., J. R. Cuento y M. SÁnchez Alfaro } \\
\text { (1995 [1994]): Gramática de español como lengua extranje- } \\
\text { ra. Madrid, Edelsa. }\end{array}$ \\
\hline $\begin{array}{l}\text { Determinación } \\
\text { de público meta }\end{array}$ & $\begin{array}{l}\text { Concebido «para su estudio inicial, su puesta al día o su pro- } \\
\text { fundización, ya que se atienden las expectativas de los alum- } \\
\text { nos, cualquiera que sea su nivel de competencia lingüística». }\end{array}$ \\
\hline $\begin{array}{l}\text { Descripción de otros } \\
\text { aspectos significativos }\end{array}$ & $\begin{array}{l}\text { Se persigue «la correcta expresión en español, con los dobles } \\
\text { pilares de la exactitud teórica de la norma y la elección ade- } \\
\text { cuada de los actos de habla». } \\
\text { Los ejemplos se encuentran separados de la explicación gra- } \\
\text { matical y van en cursiva. } \\
\text { «Numerosas muestras extraídas del habla cotidiana ejempli- } \\
\text { fican las normas gramaticales*». }\end{array}$ \\
\hline
\end{tabular}

* Todas las citas de esta obra se encuentran en González Hermoso, Cuento y Sánchez Alfaro ([1994] 1995: 3).

** Matte Bon (1992: vi). 
Tabla 7

\begin{tabular}{|c|c|}
\hline \multicolumn{2}{|l|}{ Texto 7: Mat } \\
\hline Descripción bibliográfica & $\begin{array}{l}\text { Matte Bon, Francisco (1992 [2004]): Gramática Comunica- } \\
\text { tiva del español. Madrid, Edelsa. Dos tomos. }\end{array}$ \\
\hline $\begin{array}{l}\text { Determinación } \\
\text { de público meta }\end{array}$ & $\begin{array}{l}\text { - Dirigida a hablantes de español como lengua materna y LE. } \\
\text { - Sin perseguir la exhaustividad, se ha intentado dar cabida en } \\
\text { ella a todos los problemas que tienen profesores y alumnos } \\
\text { de E.LE. } \\
\text { - No se persigue fomentar el aprendizaje autónomo del estu- } \\
\text { diante, dado que «nace en el aula y para el aula**». }\end{array}$ \\
\hline $\begin{array}{l}\text { Descripción de otros } \\
\text { aspectos significativos }\end{array}$ & $\begin{array}{l}\text { - Los ejemplos que se recogen aparecen en negrita y en párra- } \\
\text { fos separados del resto de explicaciones gramaticales. } \\
\text { - Los sustantivos se encuentran siempre acompañados del ar- } \\
\text { tículo para señalar su género. } \\
\text { - Desconocemos la procedencia de estos ítems ejemplificati- } \\
\text { vos: sí se especifica que se han limitado mucho los fragmen- } \\
\text { tos literarios. }\end{array}$ \\
\hline
\end{tabular}

Tabla 8

\begin{tabular}{|c|c|}
\hline \multicolumn{2}{|l|}{ Texto 8: San } \\
\hline Descripción bibliográfica & $\begin{array}{l}\text { SÁnchez, Aquilino, ERnesto Martín y J. A. Matilla (1995 } \\
\text { [1980]): Gramática práctica de español para extranjeros. } \\
\text { Madrid, Sociedad General Española de Librería. }\end{array}$ \\
\hline $\begin{array}{l}\text { Determinación de } \\
\text { público meta }\end{array}$ & $\begin{array}{l}\text { - Apoyo del manual Español en directo. } \\
\text { - Se busca un «entendimiento fácil, práctico y directo por par- } \\
\text { te del alumno»*. }\end{array}$ \\
\hline $\begin{array}{l}\text { Descripción de otros } \\
\text { aspectos significativos }\end{array}$ & $\begin{array}{l}\text { - Los ejemplos aparecen en columnas independientes y en } \\
\text { ocasiones en negrita para resaltar algún aspecto. } \\
\text { - Aparecen numerados. }\end{array}$ \\
\hline
\end{tabular}

\subsection{Metodología}

Tras la selección de los textos, hemos despojado los ejemplos pertenecientes a los apartados del sustantivo, del adjetivo y del artículo9; ahora bien, no se han tenido en cuenta los

* Sánchez Pérez, Martín y Matilla ([1980] 1995: 5).

9 Hemos trabajado considerando la unidad léxica equivalente a la palabra, entendida esta desde el punto de vista ortográfico delimitada por espacios en blanco o signos gráficos. Somos conscientes de la utilidad de la consideración de unidades léxicas monoverbales y de lexías complejas; no obstante, no vamos a tener en cuenta esta distinción en nuestro estudio puesto que para los recuentos estadísticos realizados ha sido de mayor rentabilidad partir de aquel concepto como unidad de análisis e investigación. 
nombres propios. A continuación, hemos procedido al etiquetado de las voces, de manera que junto a cada una de ellas hemos incluido la referencia a la obra en la que aparecen, la página y el aspecto gramatical que ilustran.

Sirva como ejemplo la siguiente palabra:

\section{Ágil (Mat 185 gen)}

De la presentación se desprende que ágil aparece en la gramática de Matte Bon en la página 185 para ilustrar algún aspecto relacionado con el género ${ }^{10}$.

Una vez realizado este etiquetado, hemos utilizado el programa de concordancias SCP (Simple Concordance Program), con el que hemos obtenido un documento con el léxico y sus representaciones en las diferentes obras. Copiamos una entrada del documento resultante a manera de muestra:

$\begin{array}{ll}\text { Actor } & \\ \text { San } & \text { Actor (San 18 gen) } \\ \text { Mat } & \text { Actor (Mat 180 gen) } \\ \text { Gon } & \text { Actor (Gon } 34 \text { gen) } \\ \text { Lob } & \text { Actor (Lob 147 gen) } \\ \text { Cas } & \text { Actor (Cas } 8 \text { gen) } \\ \text { Alo } & \text { Actor (Alo 18 gen) }\end{array}$

Las referencias a las gramáticas se encuentran ordenadas cronológicamente, con lo que de una simple ojeada podremos ver las apariciones de las voces a lo largo del tiempo. Además, las obras dirigidas a profesores se encuentran en negrita para poder diferenciar estos textos de los dirigidos a alumnos.

Con este documento, base en nuestro estudio, se han llevado a cabo diferentes análisis estadísticos del léxico trabajado: así, se ha confrontado el número de voces que cada autor utiliza, la originalidad relativa de las mismas, etc.

A continuación, se ha procedido a comparar este vocabulario con los archivos del CREA y con algunos estudios de disponibilidad y frecuencia léxica, con el fin de poder analizar los ejemplos incluidos en las gramáticas desde el punto de vista de la rentabilidad que de ellos podrían extraer los estudiantes que, a la vez que se dedican al estudio de aspectos gramaticales (ya sea con la lectura directa de los textos o a través de las explicaciones del profesor), atendieran a los ejemplos presentados en cuanto a elementos plenos de significación ${ }^{11}$.

En último lugar, se han considerado las principales áreas temáticas que quedarían cubiertas con el conjunto del léxico: para llevar a cabo esta distribución se han seguido las clasificaciones en los ámbitos que ofrece el $M C E R$, esto es, se han distribuido los ítems léxicos de

10 Las abreviaturas utilizadas son las siguientes: Gen (Género); Num (Número); Def (Definición); Pos (Posición en el sintagma); For (Formación); Der (Derivado); Exp (Alguna otra explicación que no tiene cabida en los apartados anteriores).

11 Ha de aclararse que todas estas comparaciones se han hecho desde la base del singular, en el caso de los sustantivos, y del masculino singular, en el caso de los adjetivos. Además, hemos respetado las grafías propuestas por las gramáticas para hacer las confrontaciones (como en el caso de posbélico, para el que habría sido posible buscar también por postbélico). 
las gramáticas en los ámbitos personal, público, profesional y educativo, ofreciendo en cada caso una sola clasificación de cada una de las voces analizadas con el fin de poder contar con datos numéricos absolutos sobre los que reflexionar.

\section{Estudio}

Las gramáticas estudiadas recurren a la ejemplificación de las explicaciones gramaticales a través de palabras aisladas o frases. En la mayor parte de los casos desconocemos el origen de estos ítems léxicos: solamente podemos constatar que en Alo se ha tenido en cuenta el nivel de los estudiantes para graduar las muestras de lengua incluidas o que en Mat se han limitado los fragmentos con origen literario.

\subsection{Análisis cuantitativo por autores}

Tomando los nombres que aparecen como ejemplos de cuestiones relacionadas con el sustantivo, el adjetivo y el artículo en el corpus, obtuvimos una cifra de términos que supera las 2700 entradas. Ahora bien, tras utilizar el programa de concordancias, y así reagrupar las mismas voces que aparecían en más de una obra, hemos obtenido un total de 1744 palabras diferentes que aparecen como ejemplos en los textos estudiados.

No todas las gramáticas tienen un número parecido de voces, igual que no todas las obras dedican el mismo espacio al estudio de estas partes de la oración. De media, podríamos decir que cada obra incluye casi 340 palabras: sin embargo, la realidad muestra que son solo cuatro los textos cercanos a esta cifra y que, por tanto, hay variaciones muy significativas entre las unidades léxicas aportadas por las gramáticas. En un extremo, con cerca de 1000 voces diferentes, Lob, que, como recordamos, es la obra que sirve de apoyo al manual Español 2000, es decir, un texto eminentemente dirigido a estudiantes. Se podría concluir que los textos para profesores contienen menos ejemplos, porque de las tres obras con menor número de estos, dos están dirigidas al profesorado. No obstante, está concebido para los alumnos el material que menos ejemplos incluye: Cas. Esta gramática está delimitada por el nivel de los estudiantes a los que va dirigida: se trata del nivel A1. Tal limitación en contenidos gramaticales se ha visto relacionada en este caso con una limitación en el número de ejemplos incluidos para clarificar tales contenidos: parece lógico que a menor profundización teórica sea necesario un menor número de ejemplos. Ahora bien, hemos manejado también otros manuales restringidos por el nivel de español de sus destinatarios -como es el caso Alo, destinado a estudiantes que tengan hasta un nivel B1en los que el número de ejemplos era mucho mayor, con lo que el nivel de los alumnos no parece tampoco ser la causa final que determine esta selección. La concepción de la lengua y del aprendizaje de esta que subyace en las gramáticas no se alza tampoco como elemento diferenciador en este apartado, dado que textos más netamente comunicativos o estructurales ofrecen similares características. En suma, da la impresión de que simplemente hay que buscar un deseo de abreviar y simplificar las obras para justificar una escasa presencia del ejemplo gramatical. 
Tabla 9

\begin{tabular}{|l|c|}
\hline Gramática & Número de ejemplos \\
\hline San & 364 \\
\hline Mat & 336 \\
\hline Gon & 273 \\
\hline Lob & 987 \\
\hline Cas & 37 \\
\hline Gut & 140 \\
\hline Lop & 263 \\
\hline Alo & 331 \\
\hline
\end{tabular}

Como puede apreciarse, hay dos obras que marcan las dos opciones extremas, Lob y Cas, mientras que las demás se posicionan de manera más o menos parecida en el número de ítems léxicos.

Dado que hemos trabajado con adjetivos y sustantivos, también podrían establecerse diferencias entre las obras según el número de ejemplos relacionados con cada una de estas partes de la oración. Sin entrar en el análisis detallado de cada texto, es fácil poder afirmar que los nombres sustantivos son mayoría en el cómputo general de todas las voces. De hecho, solamente Gut se aproxima ligeramente a la equiparación entre el número de sustantivos y el número de adjetivos. La norma parece ser que el porcentaje de sustantivos sea mucho más elevado que el de los adjetivos, ya que todas las obras destinan mucho más espacio a la explicación de fenómenos relacionados con aquellos.

El tratamiento de los ejemplos a través del programa de concordancias nos ha permitido la delimitación de la frecuencia de los términos estudiados. Lo más habitual es que las voces solamente se documenten en una gramática (esto ocurre en más del 70\% de los casos), aunque también nos encontramos ítems léxicos en varios o incluso en todos los materiales. Todo ello da cuenta de la originalidad de las obras con respecto a cualquier fuente: de hecho, apenas cuarenta voces se registran en seis o más textos, por lo que todo hace pensar que los criterios de selección del léxico de los ejemplos han sido bastante dispares.

Las palabras que aparecen en todas las gramáticas analizadas son las siguientes: alto, casa, estudiante, hombre, mesa, mujer y padre. Se trata de siete entradas de las que solo dos son adjetivos, por lo que se respeta a grandes rasgos lo que venía siendo la norma en la distribución de estas dos clases de palabras ${ }^{12}$. Como veremos más adelante, se trata de voces pertenecientes al ámbito personal del aprendiente según la clasificación del MCER. Nos encontramos ante nombres de significación concreta de realidades presentes en todas las culturas: son palabras prototípicas aptas para llevar a cabo cualquier tipo de ejemplificación. Se corresponden con lo que algunos autores han denominado palabras no vinculadas a la cultura (culture-free), porque son comunes a la existencia humana ${ }^{13}$ : estas voces conforman una parte importante del vocabulario básico de una lengua.

12 Tengamos en cuenta, además, que estudiante, que aparece en el diccionario de la Real Academia como adjetivo, es frecuentemente utilizado como sustantivo, como también nos indica este mismo repertorio lexicográfico.

13 Cfr. Fuster y Martí (2000: 100-105). 
Todas estas voces estarían dentro de lo que algunos autores han considerado vocabulario fácil de aprender desde el punto de vista intrínseco, ya que se trata de sustantivos de poca longitud, de gran frecuencia y utilidad para el estudiante, con un significado concreto ${ }^{14}$.

Se documentan en siete de las ocho gramáticas las siguientes voces: agua, bueno, día, español, grande, libro, madre, malo, pantalón y pobre. Todas estas palabras se encuentran en la línea de la serie anterior, es decir, voces de carácter bastante prototípico: sin embargo, aquí se aprecia ya la aparición de voces vinculadas a excepciones de la lengua española, tales como agua (que como sustantivo femenino que comienza por $a$ tónica toma el artículo determinado el); día (sustantivo masculino que acaba en a); bueno, malo y grande (adjetivos que sufren una apócope al ser antepuestos al sustantivo al que califican $)^{15}$. La inclusión de estas últimas palabras, de este modo, estaría estrechamente relacionada con la explicación de ciertas excepciones con respecto a la norma lingüística del español y no tanto con su carácter prototípico.

\subsection{Frecuencia y disponibilidad léxica}

\subsubsection{Frecuencia}

Hay autores que han diferenciado las unidades léxicas instrumentales o generales de las unidades léxicas específicas o temáticas (Widdowson, 1983). La utilidad o rentabilidad de las primeras se relaciona con su gran capacidad de sustitución en el discurso: precisamente por ello, a su vez presentan un significado muy vago. El profesor deberá atender a la enseñanza de estas unidades, por un lado, y a ciertas unidades temáticas relacionadas con los ámbitos de interés de los alumnos.

El vocabulario instrumental estaría formado por unidades léxicas generales o hiperónimos como persona, lugar objeto, cosa; flor, animal, casa, zapato, pájaro, mueble o tienda; y otras unidades léxicas útiles, como palabras referidas al color, a la forma, al tamaño o a la materia. La mayor parte de estas voces instrumentales aparece en nuestro corpus, por lo que al menos este ámbito parece más o menos cubierto ${ }^{16}$ : las gramáticas que más ejemplos de este tipo contienen son las de Lob y Gon, mientras que las que menos son las de Lop y Cas.

14 Izquierdo Gil (2004: 79-81) repasa las características intrínsecas que hacen del vocabulario algo fácil o difícil de aprender siguiendo las teorías de autores como Nation. Los sustantivos se convierten en la categoría gramatical más fácil de memorizar; dentro de estos, los de significación concreta, de fácil visualización, se retienen con menos dificultad. La utilidad de las voces lleva también a su mejor almacenamiento: esta dependerá de las necesidades e intereses de los estudiantes. Como veremos más adelante, la frecuencia está relacionada con análisis estadísticos de la lengua y muy vinculada a esta se encuentra la longitud: si tomamos un recuento de las voces más recurrentes en las lenguas descubriremos que todas ellas tienen un escaso cuerpo fónico.

15 Un estudio similar que llevamos a cabo con las gramáticas del Siglo de Oro nos permite afirmar que las voces más utilizadas como ejemplos han variado poco con el paso de los siglos. En las gramáticas áureas encontramos como más frecuentes las siguientes voces que se documentaban en más de veinte tratados: bueno, hombre, grande, malo, mano, agua, mujer y rey. Excepto mano y rey, la coincidencia es total. Véase Esteba (2006).

16 No obstante, si comparamos el léxico instrumental que Izquierdo Gil (2004: 295) determina para adolescentes que cursan $4^{\text {ème }}$ en el sistema educativo francés veremos que alrededor de un $40 \%$ de estas voces no se recogen en nuestro corpus. Esta autora había elaborado dicha lista con la ayuda de diversos diccionarios de frecuencias y repertorios lexicográficos específicamente dedicados a la enseñanza del español para extranjeros. 
Podremos localizar con facilidad los términos instrumentales porque serán los que más encontremos en listados de frecuencia. Como señaló Alvar Ezquerra (2005: 20), para conocer la frecuencia de las palabras podemos recurrir a las indicaciones que nos proporcionan los corpus o los diccionarios de frecuencia. Los corpus no son índices léxicos en sentido estricto, pero gozan de una gran objetividad y representatividad lingüística gracias al gran número de palabras que incluyen. Sin embargo, normalmente no ofrecen frecuencias. Los diccionarios de frecuencia de los que disponemos para el castellano, por su parte, resultan antiguos. Por ello, en el caso de nuestro estudio, hemos decidido complementar la consulta de ambas fuentes, corpus y diccionarios.

Hemos procedido al contraste de los términos con los datos del corpus académico CREA limitados a la franja 1987-2007, que se corresponde aproximadamente con las fechas de publicación de las obras ${ }^{17}$. De esta comparación hemos obtenido datos llamativos, tales como que 17 voces no se registran ni una sola vez durante este periodo, o que más de 200 lo hacen en menos de cincuenta ocasiones. Quiere esto decir que voces como estas no van a aparecer con demasiada frecuencia en textos generales a los que se enfrente el estudiante de español y que, por ello, no serán muy rentables en su proceso de enseñanza aprendizaje (aunque ello dependerá, sin duda, de los ámbitos temáticos de interés de los aprendientes). Además, la mayor parte de estos dos centenares son palabras que solo aparecen en una de las gramáticas estudiadas, normalmente $L o b$, texto para alumnos que incluye el mayor número de ejemplos.

Algunas de estas voces del corpus menos representadas en el CREA pertenecen a jergas profesiones, tales como braquicéfalo, lexicólogo o fonema; otras son términos coloquiales como bodorrio, padrazo o chiquitín; en otros casos nos encontramos con topónimos, como dublinés, bergamasco o cairota; algunos términos prefijados no aparecen tampoco en el DRAE, tales como superbueno o archiconocido; hay también voces de otras lenguas (lor, disk, market) y palabras referidas a realidades no demasiado frecuentes en la cultura del s. XXI (quitasol, papisa o mesnada $)^{18}$.

Por otro lado, serán muchas las ocurrencias en el CREA de nombres que forman parte de unidades léxicas pluriverbales: este es el caso de mejor (a lo mejor) o ejemplo (por ejemplo).

Una vez comparados nuestros datos con las voces del CREA, los hemos confrontado con algunos diccionarios de frecuencia ${ }^{19}$. En el caso del clásico de I. Rodríguez Bou de 1952, todos los nombres que se incluyen entre las 87 unidades léxicas más frecuentes aparecen en

17 Habría sido preferible poder contar con unas listas de frecuencia léxica en las que el componente oral estuviera más presente, ya que en el CREA los textos orales constituyen un 10\% del total recogido. Autores como Ávila (1999) defienden que las listas fundamentadas en textos orales deben priorizarse a la hora de seleccionar léxico para la enseñanza a los extranjeros si deseamos que estos interaccionen principalmente a través de este canal. En cualquier caso, disponemos de menos medios en este sentido porque existen ciertas limitaciones que reducen la cantidad de repertorios que tengan en cuenta estas variedades.

18 «El léxico es algo cambiante, entre otros motivos porque refleja la realidad extralingüística, también cambiante», M. Alvar Ezquerra (2005: 24). Así, hay voces que se registran en el diccionario de García Hoz de 1953 y que no aparecen en el proyecto Cumbre, por ejemplo. Se trata en muchos casos de términos administrativos, políticos o religiosos: ello se debe a que en aquella época los textos bíblicos y clásicos ocupaban tres cuartas partes de las muestras. Por ello, la aparición de ciertas palabras en los diccionarios de frecuencias va a estar también muy relacionada con las fuentes elegidas para el corpus.

19 Gracias a los datos recogidos por Alvar Ezquerra (2005). 
nuestras gramáticas ${ }^{20}$; si ampliamos el espectro a las 112 siguientes, sí podemos encontrar algunas ausencias en el corpus trabajado ${ }^{21}$. En el caso de un diccionario de frecuencias más moderno, el de Alameda y Cueto, dentro de los 160 ítems más frecuentes apenas hay cuatro voces que no se registran en nuestros textos ${ }^{22}$. Todo ello parece indicar que la mayor parte de las unidades más recurrentes en nuestra lengua aparece recogida en las gramáticas del corpus analizado sin contar con grandes ausencias. No obstante, más de 20 de ellas solo aparecen en una o en dos gramáticas: quiere esto decir que si bien en el total del léxico estudiado sí hay grandes coincidencias con los resultados de los diccionarios de frecuencia, no todas las voces se encuentran en todos los textos del corpus. En otras palabras, no hay una gramática que recoja todos estos ítems de gran frecuencia y solo entre todas ellas se reparten estas unidades. En cualquier caso, las gramáticas de Lob y Mat, la primera concebida para alumnos y la segunda para alumnos y profesores, son las que más términos frecuentes incluyen.

A pesar de que muchas voces de alta frecuencia no se encuentran en todas las gramáticas, las voces registradas en todos los textos del corpus están también entre las más frecuentes en estos repertorios: la excepción la conformaría estudiante, que ni aparece entre las más usuales en los diccionarios ni se sitúa por encima de las 4000 apariciones en el CREA ${ }^{23}$.

En fin, la documentación en las gramáticas de muchas de las primeras formas que aparecen en estos elencos de frecuencia nos garantiza que se trata no solo de las más abundantes, sino de las que tienen un mayor rendimiento funcional. Por ello, como señalan autores como Alvar Ezquerra (2005: 27) son las que tendríamos que enseñar en primer lugar ${ }^{24}$.

\subsubsection{Disponibilidad}

Con los estudios de disponibilidad léxica tendremos acceso al conjunto de léxico temático que queramos trasmitir a los estudiantes, el cual solía ocupar un puesto muy posterior al del léxico instrumental en los diccionarios de frecuencia. Se trata, en este caso, de unidades latentes de la lengua que aparecen en el discurso del hablante en cuanto se tiene en cuenta un cierto tema.

20 Estas unidades nominales más frecuentes son, por orden alfabético, agua, bueno, casa, día, escuela, flor, gato, grande, libro, maestro, mamá, niño, papá, perro y vez.

21 Los nombres que no encontramos son pájaro, dios, cuadro, juego, nombre, mundo, lindo, luna, río, muchacho y muñeca.

22 Nos referimos a mundo, forma, fin y cuerpo.

23 Se trata, en este caso, de un nombre muy vinculado al contexto de uso de las gramáticas, al contexto reglado de aprendizaje en el aula. Es una palabra útil en el entorno del alumno pero no frecuente en las muestras lingüísticas generales. Estaría incluida en lo que algunos autores han venido a denominar vocabulario de la escuela (Nation 1990: 209).

24 Serían las que aparecerían en los libros que con el título de Vocabulario básico o Diccionario básico aparecen en las estanterías de las librerías. Fajardo Aguirre (1993) ha estudiado las características y limitaciones de estos materiales que se quedan en la consideración de la frecuencia léxica para su elaboración. Así, por ejemplo, obtienen puestos muy diferentes los días de la semana en estos recuentos, cuando, al menos para su didáctica, deberíamos presentárselos juntos a los estudiantes. 
Podría decirse que el vocabulario fundamental de una lengua debería ser una conjunción entre el léxico básico y el léxico disponible. Por ello, es necesario identificarlo para hacer cualquier planificación docente ${ }^{25}$.

Hemos tomado como referencia para el cotejo con el vocabulario disponible cinco centros de interés extraídos de artículos sobre estudios realizados a hablantes nativos de español y a estudiantes extranjeros de nuestra lengua, que coincidían en bastantes de las elecciones ${ }^{26}$. Se trata de los ámbitos 01. Partes de la casa, 02. Ropa, 03. Alimentos y bebidas, 04. La ciudad y 05 . Profesiones y oficios. En estos estudios se les pidió a los informantes que completaran cada ámbito con veinte términos.

De la comparación que hemos llevado a cabo entre los ejemplos del corpus y estos términos extraemos que son 68 las palabras que tienen en común, es decir, presentan alrededor de un $36 \%$ de este léxico disponible. Además, la mayor parte de estas voces se documentan en una o dos gramáticas del corpus (de hecho, 25 aparecen solo en una). Una vez más, Lob y Mat son los textos que mejor ilustran esta disponibilidad léxica.

Por centros de interés, el que mejor aparece representado es el de las profesiones, con 21 términos. En cualquier caso, siempre contamos con alrededor de una decena de coincidencias como mínimo en cada ámbito.

Por lo general, las voces mejor representadas son aquellas que tenían en común las encuestas a españoles y a extranjeros (35 términos); tras estas, las que solamente recogen los extranjeros (22) y finalmente las que solo apuntaron los españoles $(11)^{27}$.

\section{3. Ámbitos de significación}

Las más frecuentes o no, las más disponibles o no, las voces que sirven de ejemplos gramaticales, ¿qué ámbitos de significación cubren? ¿En qué contextos, por tanto, podría utilizarlas los estudiantes? Para contestar a esta pregunta hemos llevado a cabo una clasificación del léxico desde el punto de vista del significado atendiendo a la parcelación en ámbitos que introduce el MCER, esto es, en los ámbitos personal, público, profesional y educativo. Rea-

25 No obstante, tanto Benítez (1993, 1994) como Maciel (1994) han destacado las diferencias que existen entre el léxico de los manuales y el de los repertorios de léxico disponible.

26 Los estudios de disponibilidad que barajábamos para la investigación no se correspondían plenamente con nuestros intereses. Por ello, hemos decidido comparar nuestros datos con los que se ofrecen en el artículo de Galloso Camacho y Prado Aragonés (2005). Estas, a su vez, se sirven de las investigaciones de una tesina de licenciatura inédita a la que no hemos podido tener acceso: C. Sánchez Gómez (2003), Disponibilidad léxica en alumnos de español como lengua extranjera, Universidad de Huelva.

Se han publicado otros artículos en los que se comparan los resultados de encuestas sobre léxico disponible en alumnos extranjeros y alumnos españoles: Carcedo (2000) se centra en los aspectos culturales que hacen disímiles las producciones de los hablantes de español como LM y las de los hablantes de español como LE.

27 Varela Navarro (2006: 52 y ss.) hace una propuesta de selección de vocabulario panhispánico por ámbitos de significación: colores, familia, partes del cuerpo, ropa, actividades cotidianas, oficina, partes de la casa, la casa, objetos colocados en la mesa para comer, objetos y muebles del cuarto de baño, alimentos, fruta, bebidas, actividades de tiempo libre, animales, deportes, verbos de movimiento, música, carácter, medios de transporte, naturaleza, ciudad, tiempo atmosférico, enfermedad, profesiones, sentimientos.

Tengamos en cuenta que hemos tomado una muestra de estudios de disponibilidad. Deberían barajarse análisis que tengan en cuenta diferentes variedades diatópicas (Varela Navarro 2006: 17-18; 23-25). 
lizar un trabajo de este tipo ha conllevado clasificar voces que aparecen descontextualizadas frecuentemente, algunas de ellas polisémicas.

En cualquier caso, más allá de estas dificultades, parece claro que la inmensa mayoría de las voces analizadas se relaciona con el ámbito personal del hombre (más de un millar, entre las cuales las más representadas en todas las obras); en torno a 400 se vinculan con el público; algo más de 150 con el profesional; y solo una treintena con el educativo. Con tal distribución, constatamos que se presentan sobre todo voces útiles para todo tipo de intercambios lingüísticos y transacciones no marcadas por un carácter público o profesional ni ligadas al contexto educativo de uso. Servirían, así pues, para situaciones generales de comunicación relacionadas con cursos generales de lengua española.

\section{Conclusiones}

Como era de esperar, desde un corpus heterogéneo, que se constituyó con el fin de presentar una visión de conjunto del tema, hemos constatado un uso diverso del ejemplo gramatical. Así, hemos trabajado con gramáticas con menos de cincuenta ejemplos nominales y otras con casi un millar. No parece que exista en cualquier caso una tendencia definida que determine que el número de ejemplos de las obras esté relacionado con el público receptor de las mismas, ni siquiera con el método lingüístico que sustenta los textos.

Las obras del corpus seleccionan un amplio abanico de voces para los ejemplos: quiere ello decir que o bien no utilizan los mismos criterios de selección objetiva o bien estos han sido total o parcialmente sustituidos por criterios subjetivos de limitación. Se aprecia una gran originalidad y libertad en la selección del léxico ejemplificativo, el cual suele corresponderse con el ámbito personal de significación, es decir, de utilidad para transacciones diarias relacionadas con el hablante y con su entorno más cercano.

No obstante, hay un grupo de voces que aparece en todas las obras: se trata de voces culture-free, muy prototípicas y válidas para prácticamente todo tipo de ejemplificaciones. Formarían parte del vocabulario instrumental de la lengua (serían las voces más recurrentes en los vocabularios de frecuencia) con el que el estudiante puede interactuar en todo tipo de textos. Es un gran acierto, por tanto, que figuren en todas las gramáticas.

Sería recomendable que, junto a estas, aparecieran voces temáticas relacionadas con los ámbitos de interés de los estudiantes. Junto con el léxico atemático sería necesario incluir una serie de unidades de léxico temático seleccionado a través de diccionarios de disponibilidad y, sobre todo, confiando en el buen criterio pedagógico de los profesores. Nuestros datos nos demuestran que, si bien hay coincidencias significativas entre los ejemplos y el léxico frecuente de la lengua, menos son las que se encuentran en lo que respecta a la disponibilidad.

No parece tampoco que haya diferencias en el tipo de léxico tomado según el público de las gramáticas. Simplemente se intuye que sea cuestión de número: cuantas más voces se incluyen, más elementos frecuentes y disponibles, y viceversa. No obstante, también las obras con más ejemplos dan mayor cabida a palabras que difícilmente encontrará el alumno en sus intercambios lingüísticos cotidianos.

Presentada una visión general de los ejemplos gramaticales, parece que se presta una limitada atención a que estos se correspondan con unidades frecuentes y disponibles. Ello nos lleva a sugerir, para finalizar, la implementación de la planificación del léxico que se lleva al aula de E.LE gracias a una mayor toma de conciencia sobre la selección de los términos que 
funcionan como ejemplos sea del discurso gramatical de textos que leen los estudiantes, sea del discurso pedagógico del profesor. Creemos que el contacto con ejemplos seleccionados según los intereses de los estudiantes podría conllevar o bien un aprendizaje implícito (propio de los niveles más altos de aprendizaje), o bien un necesario repaso de formas ya trabajadas con el grupo meta.

\section{Referencias bibliográficas}

Alvar Ezquerra, M. (2005): «La frecuencia léxica y su utilidad en la enseñanza del español como lengua extranjera» en Castillo Carballo, A. (coord.): Las gramáticas y los diccionarios en la enseñanza del español como segunda lengua: deseo y realidad. Actas del XV Congreso Internacional de Asele. Sevilla, Universidad de Sevilla, págs. 19-39.

Alvar Ezquerra, M. y J. A. Villena Ponsoda (coords.) (1994): Estudios para un corpus español. Málaga, Universidad de Málaga.

Ávila Muñoz, A. M. (1999): Léxico de frecuencia del español hablado en la ciudad de Málaga. Málaga, Universidad de Málaga.

Benítez Pérez, P. (1994): «Léxico real / léxico irreal en los manuales de español para extranjeros», en Montesa Peydró, S. y A. Garrido Moraga (eds.): Actas del Segundo Congreso Nacional de Asele. Español para extranjeros: didáctica e investigación. Málaga, Universidad de Málaga, págs. 325-334.

Benítez Pérez, P. y J. Zebrowski (1993): «El léxico español en los manuales polacos», en Montesa Peydró, S. y A. Garrido Moraga (eds.): El español como lengua extranjera: de la teoría al aula. Actas del Tercer Congreso Nacional de Asele. Málaga, Universidad de Málaga, págs. 223-230.

Carcedo González, A. (2000): «Índices léxico-estadísticos y graduación del vocabulario en la enseñanza de ELE (aspectos culturales)», en Franco, M., C. Soler, J. de Cos, M. Rivas y F. Ruiz (eds.): Nuevas perspectivas en la enseñanza del español como lengua extranjera. Actas del X Congreso Internacional de Asele. Cádiz, Universidad de Cádiz, págs. 175-183.

Castillo Carballo, A. (coord.) (2005): Las gramáticas y los diccionarios en la enseñanza del español como segunda lengua: deseo y realidad. Actas del XV Congreso Internacional de ASELE. Sevilla, Universidad de Sevilla.

CONSEJo DE EuRopa (2002): Marco común europeo de referencia para las lenguas: aprendizaje, enseñanza, evaluación. Madrid, Instituto Cervantes, Ministerio de Educación, Cultura y Deporte, Anaya.

De Miguel García, M. L. (2005): «La enseñanza del léxico del español como lengua extranjera. Resultados de una encuesta sobre la metodología aplicada en el aula», Revista de Didáctica MarcoELE, 1 , págs. 1-21.

Esteba Ramos, D. (2006): Los ejemplos en las gramáticas del español como lengua extranjera: Siglo de Oro. Málaga, Universidad de Málaga.

Fajardo Aguirre, A. (1993): «Los vocabularios básicos». En Montesa, S. y A. Garrido (eds.): El español como lengua extranjera: de la teoría al aula. Actas del Tercer Congreso Nacional de Asele. Málaga, Universidad de Málaga, págs. 215-222.

Fente, R., J. A. de Molina y A. Martínez (eds.): Actas de Primer Congreso Internacional de ASELE. Granada, Universidad de Granada.

Franco, M., C. Soler, J. de Cos, M. Rivas y F. Ruiz (eds.): Nuevas perspectivas en la enseñanza del español como lengua extranjera. Actas del X Congreso Internacional de ASELE. Cádiz, Universidad de Cádiz.

Fuster, M. y M. M. Martí (2000): «Contact and Basic English Vocabulary», Studies in English Language and Linguistics, 2, págs. 97-115. 
García Hoz, V. (1953): Vocabulario usual, vocabulario común y vocabulario fundamental. Madrid, CSIC.

Galloso Camacho, M. V. y J. Prado Aragonés (2005): «La estructura estadística del léxico disponible de informantes nativos e informantes de E.LE», en Castillo Carballo, A. (coord.): Las gramáticas y los diccionarios en la enseñanza del español como segunda lengua: deseo y realidad. Actas del XV Congreso Internacional de ASELE. Sevilla, Universidad de Sevilla, págs. 370-375.

García Santa Cecilia, Á. (2000): Cómo se diseña un curso de lengua extranjera. Madrid, Arco/Libros.

Gómez Molina, J. R. (2001): «La competencia léxica en la enseñanza-aprendizaje de español como L2 y LE», Mosaico, 5.

Gómez Molina, J. R. (2004): «La subcompetencia léxico-semántica». En Sánchez Lobato, J. e I. Santos Gargallo (eds.): Vademécum para la formación de profesores de español como segunda lengua L2 / lengua extranjera LE. Madrid, SGEL.

Instituto Cervantes (2006): Plan curricular del Instituto Cervantes. Madrid, Biblioteca Nueva e Instituto Cervantes.

Izquierdo Gil, M. C. (2004): La selección del léxico en la enseñanza del español como lengua extranjera. Su aplicación en el nivel elemental en estudiantes francófonos. Valencia, Universidad de Valencia.

Lenoir, P. (2000): «Former en IUFM à une utilisation critique des matériels didactiques d'espagnol publiés en France». En Actes des «Journées Angevines» sur la didactique de l'espagnol, págs. 17-29: www.paysdelaloire.iufm.fr/formation/formation_formateurs/collection_ressources/didactique_espagnol.pdf (17.05.09).

Maciel, C. (1994): Étude du vocabulaire de 4 manuels d'espagnol. Analyse statistique (Pour une lexicologie critique ou lexicologie de l'esperance). Tesis doctoral inédita. Universidad de Nantes.

Malinowski Rubio, M. P. (2000): «Algunos de los defectos más frecuentes en los manuales de autores no españoles, de español lengua extranjera (Sus orígenes, sus consecuencias y la necesidad de intervención)». En Franco, M., C. Soler, J. de Cos, M. Rivas y F. Ruiz (eds.): Nuevas perspectivas en la enseñanza del español como lengua extranjera. Actas del X Congreso Internacional de ASELE. Cádiz, Universidad de Cádiz, págs. 425-432.

Montesa Peydró, S. y A. Garrido Moraga (eds.): Actas del Segundo Congreso Nacional de Asele. Español para extranjeros: didáctica e investigación. Málaga,Universidad de Málaga.

Nation, P. (1990): Teaching and Learning Vocabulary. Boston, Heinle Publishers.

Nation, P. (2001): Learning Vocabulary in Another Language. Cambridge, Cambridge University Press.

Puren, C. (1998): Histoire des méthodologies de l'enseignement des langues. Paris, Clé International.

Real Academia Española (2001): Diccionario de la lengua española: www.rae.es.

Reinheimer, S. y L. Tasmowski (1997): Pratique des langues romanes : espagnol, français, italien, portugais, roumain. Paris, Montréal, l'Harmattan.

Richards, J. C. y T. S. Rodgers ([1998] 2003): Enfoques y métodos en la enseñanza de idiomas. Cambridge, Cambridge University Press.

Sánchez Pérez, A. (1992): Historia de la enseñanza del español como lengua extranjera. Madrid, SGEL.

Varela Navarro, M. (2006): Variedad léxica y enseñanza del léxico. Evaluación de materiales complementarios (niveles A1-B1) y propuesta de ejercicios. Memoria de máster leída en la Universidad de León, RedELE: http://www.educacion.es/redele/Biblioteca2007/MontseVarela.shtml (10-09-2009).

Widdowson, H. G. (1983): Learning Purpose and Language Use. Oxford, Oxford University Press. 